\title{
Trait correlates of distribution trends in the Odonata of Britain and Ireland
}

Gary D Powney, Steve SA Cham, Dave Smallshire, Nick J B Isaac

A major challenge in ecology is understanding why certain species persist, while others decline, in response to environmental change. Trait-based comparative analyses are useful in this regard as they can help identify the key drivers of decline, and highlight traits that promote resistance to change. Despite their popularity trait-based comparative analyses tend to focus on explaining variation in range shift and extinction risk, seldom being applied to actual measures of species decline. Furthermore they have tended to be taxonomically restricted to birds, mammals, plants and butterflies. Here we utilise a novel approach to estimate occurrence trends for the Odonata in Britain and Ireland, and examine trait correlates of these trends using a recently available trait dataset. We found the dragonfly fauna in Britain and Ireland has undergone considerable change between 1980 and 2012, with 22 and 53\% of species declining and increasing respectively. Distribution region, habitat specialism and range size were the key traits associated with these trends, where habitat generalists that occupy southern Britain tend to have increased in comparison to the declining narrow-ranged specialist species. In combination with previous evidence, we conclude that the lower trend estimates for the narrow-ranged specialists could be a sign of biotic homogenization with ecological specialists being replaced by warm-adapted generalists. 


\section{Trait correlates of distribution trends in the Odonata of Britain and Ireland}

2 Gary D. Powney ${ }^{1 *}$, Steve Cham ${ }^{2}$, Dave Smallshire ${ }^{3}$ \& Nick J.B. Isaac ${ }^{1}$

3 1. NERC Centre for Ecology \& Hydrology, Maclean Building, Benson Lane, Wallingford, Oxfordshire, OX10

$4 \quad 8 B B, U K$

5 2. British Dragonfly Society, 24 Bedford Avenue, Silsoe, Bedfordshire, MK45 4ER, UK

6 3. British Dragonfly Society - Dragonfly Conservation Group, 8 Twindle Beer, Chudleigh, Newton Abbot, TQ13

$7 \quad O J P, U K$

* Corresponding author: Gary D. Powney, NERC Centre for Ecology \& Hydrology, Maclean Building, Benson Lane, Wallingford, Oxfordshire, OX10 8BB, UK, Tel: +44 (0)1491 838800, gary.powney@ceh.ac.uk

\section{Abstract}

A major challenge in ecology is understanding what enables certain species to persist, while others decline in response to environmental change. Trait-based comparative analyses are useful in this regard as they can help identify the key drivers of decline, and highlight traits that promote resistance to change. Despite their popularity trait-based comparative analyses tend to focus on explaining variation in range shift and extinction risk, seldom being applied to actual measures of species decline. Furthermore they have tended to be taxonomically restricted to birds, mammals, plants and butterflies. Here we utilise a novel approach to estimate occurrence trends for the Odonata in Britain and Ireland, and examine trait correlates of these trends using a recently available trait dataset. We found the dragonfly fauna in Britain and Ireland has undergone considerable change between 1980 and 2012, with 22 and $53 \%$ of species declining and increasing respectively. Distribution region, habitat specialism and range size were the key traits associated with these trends, where habitat generalists that occupy 
24 southern Britain tend to have increased in comparison to the declining narrow-ranged specialist species.

25 In combination with previous evidence, we conclude that the lower trend estimates for the narrow-

26 ranged specialists could be a sign of biotic homogenization with ecological specialists being replaced by

27 warm-adapted generalists.

Introduction

Defaunation, the loss of species and populations (Dirzo et al., 2014), is occurring at an alarming rate with recent estimates suggesting that the current extinction rate is 1000 times that of the historical natural background rate (De Vos et al., 2014). These declines are driven by environmental change, particularly habitat loss and climate change, and can be measured in a number of ways, e.g. changes in distribution and abundance (Thomas et al., 2004; Biesmeijer et al., 2006; Butchart et al., 2010; Chen et al., 2011). Variation in species responses to environmental change has been found across broad taxonomic groups (Hickling et al., 2006; Angert et al., 2011) but also within taxonomic groups, i.e. between species within an order (Hickling et al., 2005). A major challenge in conservation ecology is to gain a better understanding of this interspecific variation in response to environmental change, i.e. what enables certain species to persist while others decline?

Species traits play an important role in determining species' ability to resist environmental change. For example, several studies have shown that ecological generalists out-perform specialists in times of environmental change (Walker \& Preston, 2006; Ozinga et al., 2012; Newbold et al., 2013). Such comparative trait-based analyses are popular, as the models help to identify the main drivers of change and allow the prediction of future biodiversity changes based on environmental forecasts (Fisher \& 
46

47

48

49

50

51

52

53

54

55

Owens, 2004; Cardillo et al., 2006). Previous comparative trait analyses have tended to focus on explaining variation in range shift (Angert et al., 2011; Mattila et al., 2011; Grewe et al., 2012) and extinction risk (Purvis et al., 2000; Koh et al., 2004; Cardillo et al., 2008; Cooper et al., 2008; Fritz et al., 2009). Despite its popularity, the comparative trait-based approach has seldom been applied to direct measures of species' changing status (i.e. rates of decline or increase). Currently data on such measures of decline are rare, particularly at large (e.g. national) scales and across multiple species. With the increase in public participation in biological recording, the availability of large-scale distribution datasets has increased (Silvertown, 2009). Such data tend to be collected without systematic protocols and thus contain many forms of sampling bias and noise, making it hard to detect genuine signals of change (Tingley \& Beissinger, 2009; Hassall \& Thompson, 2010; Isaac et al., 2014b). However, recent advances in analytical approaches have improved our ability to estimate reliable trends from these unstructured biological records (Isaac et al., 2014). In this study we utilise these novel approaches to estimate trends in occurrence for the Odonata in Britain and Ireland, and use species traits to test hypotheses for the interspecific variation in trends.

We chose to examine Odonata for a number of reasons. Firstly, previous trait-based comparative analyses have tended to focus on birds, mammals, plants and butterflies. Despite being highly species rich and their crucial role across ecosystems, the non-butterfly invertebrate fauna are comparatively poorly studied (IUCN, 2001; Dirzo et al., 2014). Secondly, Odonata are thought to be excellent bioindicators as they are sensitive to degradation of water ecosystems (Samways \& Steytler, 1996; Sahlén \& Ekestubbe, 2001; Lee Foote \& Rice Hornung, 2005). Thirdly, they provide a valuable ecosystem service as they feed on many insect pests (Brooks \& Lewington, 2007). Finally, the publication of a new atlas (Cham et al., 2014) and trait datasets (Powney et al., 2014) for British Odonata together constitute 
some of the best quality data of any non-butterfly invertebrate group. Previous research based on Odonata occurrence data has focussed on the impact of climate change on phenology and distribution. For example Hassall et al. (2007) discovered that emergence from overwintering had significantly advanced over the past 50 years, while Hickling et al. (2005) showed that the upper latitudinal margin shifted north between 1960 and 1995. Outside Britain, Bush et al. (2014) used species distribution models (SDMs) to predict which Australian odonates were under threat from climate change.

Several studies have utilised traits to explain variation in several aspects of Odonata ecology, but typically focus on explaining variation in species response to climate change. In terms of phenological advancement, Hassall et al. (2007) noted that spring species and those without egg diapause exhibited increased phenological shifts. Angert et al. (2011) examined trait correlates of range shift across multiple taxonomic groups, finding that exophytic Odonata species in Britain shifted further north, on average, than endophytic species. These insights, combined with extensive knowledge about their natural history (Brooks \& Lewington, 2007), form the basis of seven competing hypotheses (outlined below) that aim to explain the interspecific variation in the distribution trends among British Odonata.

All traits included in the analysis have been shown to affect species' ability to respond to environmental change. Habitat breadth is frequently related to species trends, where habitat generalists outperform specialists due to their greater ability to adapt to novel environmental conditions (Fisher \& Owens, 2004; Menéndez et al., 2006; Botts et al., 2012). Ball-Damerow et al., (2014) found evidence of the widespread expansion of habitat generalists which has led to biotic homogenization in the dragonfly fauna of California and Nevada over the last century. We test the hypothesis that Odonata in Britain and Ireland follow the patterns outlined above, with generalists out-performing specialists. Dispersal 
92 ability affects species' ability to respond to environmental pressures, with higher dispersal ability linked

93 to an enhanced ability to respond (Thomas et al., 2001; Pöyry et al., 2011; Grewe et al., 2012). Using

94 SDMs, Hof et al. (2012) found lentic (i.e. pond and lake dwelling) species had a greater ability to track

95 changes in their climatic niche. This was linked to greater dispersal ability, which is essential given the

96 ephemeral nature of their breeding sites (Hof et al., 2006). We predict lentic species will have higher

97 (more positive) trend estimates than lotic species as their increased dispersal ability enables them to persist during times of environmental change through the efficient relocation to newly suitable areas.

Geographic range size and body size are both frequently used as surrogates for a whole host of traits associated with ecological specialism and competitive ability (Gittleman, 1985; Gaston, 2003; Angert et al., 2011). We predict that widespread species and the larger, therefore more competitive species, are likely to show positive trends. Climate warming has increased the suitability of the landscape to those species that were previously limited by their lower thermal tolerance threshold (Devictor et al., 2008; Dingemanse \& Kalkman, 2008; Bellard et al., 2012), and evidence of the loss of northern species has been seen in a variety of taxonomic groups across a variety of geographic regions (Hill et al., 2002; Devictor et al., 2008; Myers et al., 2009; Foufopoulos et al., 2011). We therefore predict that southerly distributed species will show the most positive trend estimates. An additional aspect of climate change that has been linked with trends in Odonata is the increase in flood events in Britain. Species which overwinter as larvae are particularly vulnerable to flooding as they can be swept away from ideal habitat areas to unsuitable regions in which they cannot persist (Cham et al., 2014). As a result we predict

111 species that overwinter as larvae will have undergone the greatest declines. Finally we test the

112 hypothesis that flight period will be positively related with species' trend. Grewe et al., (2012) argued

113 that species with longer flight periods have increased dispersal ability, and therefore have a greater 114 capacity to adapt in response to environmental change. 


\section{Occurrence trends}

Trends were estimated from Odonata distribution records in Britain and Ireland collected by the Dragonfly Recording Network and coordinated by the British Dragonfly Society. Our analyses are based on 588,480 records of 36 native species collected between 1980 and 2012 where the recording date is known and the location was recorded to $1 \mathrm{~km}^{2}$ precision or better. As these occurrence records were collected without a specific sampling design they contain a variety of bias which inhibit their use in estimating reliable trends. For example, the number of records collected each year has increased dramatically over time (Cham et al., 2014), such that simply counting the number of occupied sites would produce biased trend estimates (Prendergast et al., 1993; Isaac et al., 2014). To account for these biases we estimated species trends using an approach based on Bayesian occupancy modelling (van Strien et al., 2013; Isaac et al., 2014). We first arranged the records into 212,574 visits, which were defined as unique combinations of date and $1 \mathrm{~km}^{2}$ grid cell (site). For each visit, each of the 36 species was coded as either recorded (1) or not-recorded (0). We then selected sites with at least three years of data, ensuring we retained only the well-sampled sites (Figure 1). Our final dataset contains 467,899 records from 157,507 visits to 11,435 sites $(64,005$ site-year combinations). We ran occupancy models for each species based on the methodology of Van Strien et al. (2013) and Isaac et al. (2014). The approach uses two hierarchically coupled sub-models, one, the state model, governs the true presence/absence of a species at a site in a given year, the second, the observation model, governs the probably of detecting that species given its presence or absence, and is therefore conditional on the state model. The detection probability per visit is a function of the number of species recorded on that visit (the 'list length': see appendix 1 for detailed model description). For each site-year combination the model estimates presence or absence for the species in question given variation in detection 
139 probability: from this the proportion of occupied sites ('occupancy') was estimated for each year.

140 Finally, within the Bayesian framework, a linear trend was fitted to these annual proportions to identify

141 a temporal trend in species occupancy. The slope of this regression of occupancy against year was used

142 as the species-specific trend measure in the cross-species comparative analysis.

\section{Species' trait data}

145 We included data on seven traits extracted from Powney et al. (2014) (Table 1). Two traits were based on characteristics of a species' distribution pattern, the first, species status, was measured as an ordinal variable based on distribution size, moving from very rare through to very widespread. Secondly, distribution region was a categorical variable that defined a species broad climatic restriction, with species classified into one of four levels, northern, southern (which included continental species from the original classification), oceanic or widespread based on their distribution pattern. We included a single morphological trait, thorax length $(\mathrm{mm})$, which was taken as the mean of multiple measurements adults are typically recorded in flight. We included two habitat based traits, habitat breadth measured the number of broad habitats a species can utilise (maximum of 6), while breeding habitat classified species based on breeding habitat preference, lentic, lotic or both. Finally, we classified species based on their overwintering stage, either eggs, larvae or both. Distribution status was coded as an ordinal centred on zero prior to the analysis. 
161

162

163

164

165

166

\section{Comparative analysis}

We used the pgls function from the R package caper (Orme, 2012) to run phylogenetically informed linear models to examine trait-trend relationships while accounting for phylogenetic non-independence (Freckleton et al., 2002). In all phylogenetically informed models, the level of phylogenetic correction (Pagel's $\lambda$ ) was estimated via maximum likelihood (Pagel, 1999; Freckleton et al., 2002). Due to data limitations we used a phylogeny based on taxonomy for the analyses. The phylogeny was built using the as.phylo function from the R package ape (Paradis et al., 2005) with nodes based on Suborder, Family, Genus and Species, and all branch lengths were set to one.

We tested seven hypotheses about the drivers of species' trends whilst incorporating uncertainty in the trend estimates of each species. To do this, we fitted 10,000 trait-trend models: in each model we selected, at random, one value from the posterior distribution of trend estimates for each species. In all 10,000 models we estimated the coefficients for each of the seven traits (described above) as fixed effects. From these models, we then calculated the mean and $95 \%$ confidence intervals for the traittrend parameter estimates across all iterations.

\section{Results}

We found substantial variation in the trend estimates between species. Of 36 species included in the analysis, 8 had negative trends and 19 had positive trends where the 95 percentiles ( 2.5 and 97.5 percentiles) did not bridge zero (Appendix 2). Species that showed the greatest declines included: Aeshna juncea and Sympetrum danae, while Anax imperator and Aeshna mixta showed the greatest increases. 
Key results from the comparative trait-analysis (Table 2 and Figure 2) showed distribution status, habitat breadth and thorax length were positively associated with species trend, while species with longer flight periods tended to have lower trend estimates (i.e. they declined relative to species with short flight periods). Distribution region was an important predictor of species trend, where southern species increased relative to oceanic and widespread species. Notable exceptions to this trend include the declines in Ischnura pumilio and Gomphus vulgatissimus both of which were classified as southern species. Northern species showed the largest increases, although this result is highly uncertain (reflected in the wide $95 \% \mathrm{Cl}$ across the 10,000 iterations). Lentic species tended to have lower trend estimates than lotic species and those species that utilise both breeding habitat strategies. Finally, there appeared to be little evidence of an influence of overwintering stage on species trend. Trends tended to be similar between species that overwinter as eggs and those that overwinter as larvae. Species that can overwinter as both eggs and larvae had the lowest average trend estimates, however this category was comprised of four species only. In general, the phylogenetic signal across the model iterations was low, with a mean of $0.035(0.0-0.36)$.

\section{Discussion}

We found that the dragonfly fauna in Britain and Ireland has undergone considerable change during recent decades, with high levels of interspecific variation in occurrence trends. We found 8 species (22\%) had declined, whereas 19 species (53\%) showed increasing trends. The large number of species with positive trends is likely to reflect the recovery of dragonfly populations in response to increased water quality in Britain since the mid-20 ${ }^{\text {th }}$ Century. Although a greater number of species increasing than declining is good news for conservation, this could reflect biotic homogenization, i.e. the fauna 
206 becoming dominated by a certain group of species, leading to the erosion of local and regional

207 difference between communities (Keith et al., 2009).

208

209 We found distribution region was a key correlate of Odonata occurrence trends, with southern species

210 tending to have higher trend estimates than the oceanic and widespread species (Figure 2). This result

211 is in line with our hypothesis that increased temperatures has increased the climate suitability of Britain

212 and Ireland for southerly distributed species. A variety of studies have provided evidence of this

213 relationship, i.e. Devictor et al. (2008) found bird communities in France between 1989 and 2006 were

214 increasingly dominated by species that prefer warmer conditions, while Lima et al. (2007) found

215 evidence of northward range expansions in warm-water adapted Portuguese algae. Hickling et al.

216 (2005) used distribution region to explain variation in range shift and expansion in British Odonata,

217 finding that southern species showed greater poleward shifts and expansions compared to northern

218 species. We found little evidence of a difference between northern and southern species, however this

219 is likely due the low number of northern species $(n=4)$ included in our dataset. Interestingly, Angert et

220 al. (2011) found no correlation between range shift and position of the northern range limit (which is

221 related to our measure of distribution region). Despite the wealth of evidence that points to climate

222 change as the likely driver of increases in southern species, we cannot ignore the role of improved water

223 quality and standing water availability in southern Britain (Hickling et al., 2005; Vaughan \& Ormerod,

224 2012; Cham et al., 2014). Durance \& Ormerod (2009) noted that improved water quality can confound

225 attempts to detect the impact of climate change on freshwater macroinvertebrates. Southern species

226 are likely to have benefitted from both the increased water quality in southern Britain and improved

227 climate suitability, while the former was the main positive driver for widespread species, this could

228 explain the greater increases in southern compared to widespread species. Not all southern species 
229 showed positive trends (notably Ischnura pumilio and Gomphus vulgatissimus), here the limited

230 expansion is likely due to a lack of suitable habitat.

232 Numerous studies have related habitat breadth to species trends and tend to find that habitat

233 generalists outperform specialists (Fisher \& Owens, 2004; Menéndez et al., 2006; Botts et al., 2012).

234 Much of the evidence of this relationship is based on studies of terrestrial organisms (Biesmeijer et al.,

235 2006; Ozinga et al., 2012; Newbold et al., 2013), with a notable exception from Ball-Damerow et al.,

236 (2014). Here, we found that the relationship holds in the Odonata fauna of the UK as habitat breadth

237 was positively correlated with occurrence trend. The likely cause of this relationship is that habitat

238 generalists have a greater ability to adapt to novel environmental conditions, which is particularly

239 important in our current climate of anthropogenically driven environmental change (Travis, 2003;

240 Newbold et al., 2013). Thorax length and distribution status (used here as a measure of range size) were

241 positively related to occurrence trends, i.e. narrow ranged, "rare", small sized species tended to have

242 lower trend estimates than wider ranging, larger species. Geographic range size and thorax length are

243 often used as surrogates for traits associated with ecological specialism and competitive ability

244 (Gittleman, 1985; Gaston, 2003; Angert et al., 2011). Therefore, as with habitat specialism above, we

245 believe this result is driven by the greater ability of competitive ecological generalists to adapt to

246 environmental change than specialists.

Hof et al. (2012) found lentic (i.e. pond and lake dwelling) species had a greater ability to track changes in their climatic niche due to their greater dispersal ability, essential given the ephemeral nature of their breeding sites. We hypothesised that the greater dispersal ability of lentic species would promote their resilience to environmental change leading to a higher average trend estimate than lotic species. The 
252 results in this study do not support our hypothesis as lentic species tended to have lower trend

253 estimates than lotic species. Differences in mean trend between lentic and lotic species are likely due to

254 differences in the impact environmental stressors (e.g. climate change, eutrophication and other forms

255 of habitat degradation), interactions between them and subsequent restoration between rivers and

256 lakes (Vaughan \& Ormerod, 2012). A study aimed at improving our understanding of the variation

257 between lentic and lotic species is a prime candidate for future work.

Finally we found that flight period was negatively related to occurrence trend, a result contrary to expectations. As with the lentic/lotic hypothesis, initially we suspected that species with greater dispersal ability would show higher trends as increased dispersal capacity increases the ability to mitigate the negative effects of environmental. We used flight period as a surrogate of dispersal ability on the premise that the longer the flight season the more time a species has to disperse (Grewe et al., 2012). It is plausible that the use of a more direct measure of dispersal ability would have produced a result that is consistent with the literature on dispersal ability and species trends. It is worth noting that the reliability of the trait-trend results depend on the accuracy of the underlying trait and trend data, and we note that within a given species, traits can vary spatially. One such plastic trait includes flight period that has been shown to vary with latitude (Corbet, 2004). Summarising this variation into a single value per trait per species is a common approach but can create noise in model results.

In conclusion, we found that a large number of dragonfly species have increased in the UK between 1980 and 2012, and is likely a response to increased water quality. We found that habitat generalists that occupy southern Britain tend to have increased in comparison to the narrow-ranged specialist species of dragonfly. We believe this reflects the impact of environmental change, particularly climate 
275

276

277

278

279

280

281

282

283

284

285

286

287

288

289

290

291

292

293

294

295

296

297

298

299

300

change, as the increased ambient temperature in Britain and Ireland better suits species that are adapted to warmer conditions. The lower trend estimates for specialist species is a cause of conservation concern as this result combined with evidence in previous studies could be a sign of biotic homogenization with ecological specialists being replaced by warm-adapted generalists.

\section{Acknowledgements}

We are indebted the British Dragonfly Society and its vast collection of volunteer recorders, without them this project would not be possible. We thank Oliver Pescott, Colin Harrower, Tom August and Louise Barwell for their advice on the data analysis. We thank Christopher Hassall and Lester Yuan for providing valuable feedback on an earlier draft of this study.

\section{References}

Angert, A.L., Crozier, L.G., Rissler, L.J., Gilman, S.E., Tewksbury, J.J. \& Chunco, A.J. (2011) Do species' traits predict recent shifts at expanding range edges? Ecology Letters, 14, 677-689.

Ball-Damerow, J.E., M'Gonigle, L.K. \& Resh, V.H. (2014) Changes in occurrence, richness, and biological traits of dragonflies and damselflies (Odonata) in California and Nevada over the past century. Biodiversity and Conservation, 23, 2107-2126.

Bellard, C., Bertelsmeier, C., Leadley, P., Thuiller, W. \& Courchamp, F. (2012) Impacts of climate change on the future of biodiversity. Ecology letters, 15, 365-377.

Biesmeijer, J.C., Roberts, S.P.M., Reemer, M., Ohlemüller, R., Edwards, M., Peeters, T., Schaffers, A.P., Potts, S.G., Kleukers, R., Thomas, C.D., Settele, J. \& Kunin, W.E. (2006) Parallel declines in pollinators and insect-pollinated plants in Britain and the Netherlands. Science, 313, 351-354.

Botts, E.A., Erasmus, B.F.N. \& Alexander, G.J. (2012) Small range size and narrow niche breadth predict range contractions in South African frogs. Global Ecology and Biogeography, 22, 567-576.

Brooks, S.J. \& Lewington, R. (2007) Field guide to the Dragonflies and Damselflies of Great Britain and Ireland, British Wildlife Publishing, Dorset. 
301 Bush, A.A., Nipperess, D.A., Duursma, D.E., Theischinger, G., Turak, E. \& Hughes, L. (2014) Continentalscale assessment of risk to the Australian odonata from climate change. PloS one, 9, e88958.

303

304

305

306

307

308

309

310

Butchart, S.H.M., Walpole, M., Collen, B., van Strien, A., Scharlemann, J.P.W., Almond, R.E.A., Baillie, J.E.M., Bomhard, B., Brown, C., Bruno, J., Carpenter, K.E., Carr, G.M., Chanson, J., Chenery, A.M., Csirke, J., Davidson, N.C., Dentener, F., Foster, M., Galli, A., Galloway, J.N., Genovesi, P., Gregory, R.D., Hockings, M., Kapos, V., Lamarque, J.-F., Leverington, F., Loh, J., McGeoch, M.A., McRae, L., Minasyan, A., Morcillo, M.H., Oldfield, T.E.E., Pauly, D., Quader, S., Revenga, C., Sauer, J.R., Skolnik, B., Spear, D., Stanwell-Smith, D., Stuart, S.N., Symes, A., Tierney, M., Tyrrell, T.D., Vié, J.-C., Watson, R. \& Hernández Morcillo, M. (2010) Global biodiversity: indicators of recent declines. Science, 328, 1164-1168.

Cardillo, M., Mace, G.M., Gittleman, J.L., Jones, K.E., Bielby, J. \& Purvis, A. (2008) The predictability of extinction: biological and external correlates of decline in mammals. Proceedings of the Royal Society B Biological Sciences, 275, 1441-1448.

Cardillo, M., Mace, G.M., Gittleman, J.L. \& Purvis, A. (2006) Latent extinction risk and the future battlegrounds of mammal conservation. Proceedings of the National Academy of Sciences of the United States of America, 103, 4157-4161.

Cham, S., Nelson, B., Parr, A., Prentice, S., Smallshire, D. \& Taylor, P. (2014) Atlas of Dragonflies in Britain and Ireland, Field Studies Council, Telford.

Chen, I.-C., Hill, J.K., Ohlemuller, R., Roy, D.B., Thomas, C.D. \& Ohlemüller, R. (2011) Rapid range shifts of species associated with high levels of climate warming. Science, 333, 1024-1026.

Cooper, N., Bielby, J., Thomas, G.H. \& Purvis, A. (2008) Macroecology and extinction risk correlates of frogs. Global Ecology and Biogeography, 17, 211-221.

Corbet, P. (2004) Dragonflies - behaviour and ecology of Odonata, Harley Books, Colchester.

Devictor, V., Julliard, R., Couvet, D. \& Jiguet, F. (2008) Birds are tracking climate warming, but not fast enough. Proceedings of the Royal Society B - Biological Sciences, 275, 2743-8.

Dingemanse, N.J. \& Kalkman, V.J. (2008) Changing temperature regimes have advanced the phenology of Odonata in the Netherlands. Ecological Entomology, 33, 394-402.

Dirzo, R., Young, H.S., Galetti, M., Ceballos, G., Isaac, N.J.B. \& Collen, B. (2014) Defaunation in the Anthropocene. Science, 345, 401-406.

Durance, I. \& Ormerod, S.J. (2009) Trends in water quality and discharge confound long-term warming effects on river macroinvertebrates. Freshwater Biology, 54, 388-405.

Fisher, D.O. \& Owens, I.P.F. (2004) The comparative method in conservation biology. Trends in Ecology \& Evolution, 19, 391-398. 
333

334

335

336

337

338

339

340

341

342

343

344

345

346

347

348

349

350

351

352

353

354

355

356

357

358

359

360

361

362

363

364

Foufopoulos, J., Kilpatrick, A.M. \& Ives, A.R. (2010) Climate change and elevated extinction rates of reptiles from Mediterranean islands. The American naturalist, 177, 119-129.

Freckleton, R.P., Harvey, P.H. \& Pagel, M. (2002) Phylogenetic analysis and comparative data: a test and review of evidence. The American Naturalist, 160, 712-726.

Fritz, S.A., Bininda-Emonds, O.R.P. \& Purvis, A. (2009) Geographical variation in predictors of mammalian extinction risk: big is bad, but only in the tropics. Ecology Letters, 12, 538-549.

Gaston, K.J. (2003) The Structure and Dynamics of Geographic Ranges, Oxford University Press, Oxford.

Gittleman, J.L. (1985) Carnivore body size: Ecological and taxonomic correlates. Oecologia, 67, 540-554.

Grewe, Y., Hof, C., Dehling, D.M., Brandl, R. \& Brändle, M. (2012) Recent range shifts of European dragonflies provide support for an inverse relationship between habitat predictability and dispersal. Global Ecology and Biogeography, 22, 403-409.

Hassall, C. \& Thompson, D.J. (2010) Accounting for recorder effort in the detection of range shifts from historical data. Methods in Ecology and Evolution, 1, 343-350.

Hassall, C., Thompson, D.J., French, G.C. \& Harvey, I.F. (2007) Historical changes in the phenology of British Odonata are related to climate. Global Change Biology, 13, 933-941.

Hickling, R., Roy, D.B., Hill, J.K., Fox, R. \& Thomas, C.D. (2006) The distributions of a wide range of taxonomic groups are expanding polewards. Global Change Biology, 12, 450-455.

Hickling, R., Roy, D.B., Hill, J.K. \& Thomas, C.D. (2005) A northward shift of range margins in British Odonata. Global Change Biology, 11, 502-506.

Hill, J.K., Thomas, C.D., Fox, R., Telfer, M.G., Willis, S.G., Asher, J. \& Huntley, B. (2002) Responses of butterflies to twentieth century climate warming: implications for future ranges. Proceedings of the Royal Society B - Biological Sciences, 269, 2163-71.

Hof, C., Brandle, M. \& Brandl, R. (2006) Lentic odonates have larger and more northern ranges than lotic species. Journal of Biogeography, 33, 63-70.

Hof, C., Brändle, M., Dehling, D.M., Munguía, M., Brandl, R., Araújo, M.B. \& Rahbek, C. (2012) Habitat stability affects dispersal and the ability to track climate change. Biology letters, 8, 639-43.

Isaac, N.J.B., van Strien, A.J., August, T.A., de Zeeuw, M.P. \& Roy, D.B. (2014) Statistics for citizen science: extracting signals of change from noisy ecological data. Methods in Ecology and Evolution, 5, 1052-1060.

Keith, S.A., Newton, A.C., Morecroft, M.D., Bealey, C.E. \& Bullock, J.M. (2009) Taxonomic homogenization of woodland plant communities over 70 years. Proceedings of the Royal Society B Biological Sciences, 276, 3539-44. 
365

366

367

368

Koh, L.P., Sodhi, N.S. \& Brook, B.W. (2004) Ecological correlates of extinction proneness in tropical butterflies. Conservation Biology, 18, 1571-1578.

Lee Foote, A. \& Rice Hornung, C.L. (2005) Odonates as biological indicators of grazing effects on Canadian prairie wetlands. Ecological Entomology, 30, 273-283.

Lima, F.P., Ribeiro, P.A., Queiroz, N., Hawkins, S.J. \& Santos, A.M. (2007) Do distributional shifts of northern and southern species of algae match the warming pattern? Global Change Biology, 13, 25922604.

Mattila, N., Kaitala, V., Komonen, A., Päivinen, J. \& Kotiaho, J.S. (2011) Ecological correlates of distribution change and range shift in butterflies. Insect Conservation and Diversity, 4, 239-246.

Menéndez, R., Megías, A.G., Hill, J.K., Braschler, B., Willis, S.G., Collingham, Y., Fox, R., Roy, D.B. \& Thomas, C.D. (2006) Species richness changes lag behind climate change. Proceedings of the Royal Society B - Biological Sciences, 273, 1465-70.

Myers, P., Lundrigan, B.L., Hoffman, S.M.G., Haraminac, A.P. \& Seto, S.H. (2009) Climate-induced changes in the small mammal communities of the Northern Great Lakes Region. Global Change Biology, $15,1434-1454$.

Newbold, T., Scharlemann, J.P.W., Butchart, S.H.M., Sekercioğlu, C.H., Alkemade, R., Booth, H., Purves, D.W. \& Sekercioglu, C.H. (2013) Ecological traits affect the response of tropical forest bird species to land-use intensity. Proceedings of the Royal Society B - Biological Sciences, 280, 2012-2131.

Orme, D. (2012) The caper package: comparative analysis of phylogenetics and evolution in R. 1-36.

Ozinga, W.A., Colles, A., Bartish, I. V., Hennion, F., Hennekens, S.M., Pavoine, S., Poschlod, P., Hermant, M., Schaminée, J.H.J. \& Prinzing, A. (2012) Specialists leave fewer descendants within a region than generalists. Global Ecology and Biogeography, 22, 213-222.

Pagel, M. (1999) Inferring the historical patterns of biological evolution. Nature, 401, 877-84.

Paradis, E., Strimmer, K., Claude, J., Opgen-Rhein, R., Dutheil, J., Noel, Y. \& Bolker, B. (2005) APE: analyses of phylogenetics and evolution. $R$ package.

Powney, G.D., Brooks, S.J., Barwell, L.J., Bowles, P., Fitt, R.N.L., Pavitt, A., Spriggs, R. \& Isaac, N.J.B. (2014) Morphological and Geographical Traits of the British Odonata. Biodiversity Data Journal, 2, e1041.

Pöyry, J., Leinonen, R., Söderman, G., Nieminen, M., Heikkinen, R.K. \& Carter, T.R. (2011) Climateinduced increase of moth multivoltinism in boreal regions. Global Ecology and Biogeography, 20, 289298.

Prendergast, J.R., Wood, S.N., Lawton, J.H. \& Eversham, B.C. (1993) Correcting for variation in recording effort in analyses of diversity hotspots. Biodiversity Letters, 1, 39-53. 
Purvis, A., Gittleman, J.L., Cowlishaw, G. \& Mace, G.M. (2000) Predicting extinction risk in declining species. Proceedings of the Royal Society B - Biological Sciences, 267, 1947-52.

Sahlén, G. \& Ekestubbe, K. (2001) Identification of dragonflies (Odonata) as indicators of general species richness in boreal forest lakes. Biodiversity and Conservation, 10, 673-690.

Samways, M.J. \& Steytler, N.S. (1996) Dragonfly (Odonata) distribution patterns in urban and forest landscapes, and recommendations for riparian management. Biological Conservation, 78, 279-288.

Silvertown, J. (2009) A new dawn for citizen science. Trends in ecology \& evolution, 24, 467-71.

Van Strien, A.J., van Swaay, C.A.M. \& Termaat, T. (2013) Opportunistic citizen science data of animal species produce reliable estimates of distribution trends if analysed with occupancy models. Journal of Applied Ecology, 50, 1450-1458.

Thomas, C.D., Bodsworth, E.J., Wilson, R.J., Simmons, A.D., Davies, Z.G., Musche, M. \& Conradt, L. (2001) Ecological and evolutionary processes at expanding range margins. Nature, 411, 577-581.

Thomas, J.A., Telfer, M.G., Roy, D.B., Preston, C.D., Greenwood, J.J.D., Asher, J., Fox, R., Clarke, R.T. \& Lawton, J.H. (2004) Comparative losses of British butterflies, birds, and plants and the global extinction crisis. Science, 303, 1879-81.

Tingley, M.W. \& Beissinger, S.R. (2009) Detecting range shifts from historical species occurrences: new perspectives on old data. Trends in Ecology \& Evolution, 24, 625-633.

Travis, J.M.J. (2003) Climate change and habitat destruction: a deadly anthropogenic cocktail. Proceedings of the Royal Society B - Biological Sciences, 270, 467-73.

Vaughan, I.P. \& Ormerod, S.J. (2012) Large-scale, long-term trends in British river macroinvertebrates. Global Change Biology, 18, 2184-2194.

De Vos, J.M., Joppa, L.N., Gittleman, J.L., Stephens, P.R. \& Pimm, S.L. (2014) Estimating the normal background rate of species extinction. Conservation Biology, 29, 452-462.

Walker, K.J. \& Preston, C.D. (2006) Ecological predictors of extinction risk in the flora of lowland England, UK. Biodiversity and Conservation, 15, 1913-1942. 
1

Figure 1 The distribution and density of sites (monads) from which the trend estimates were derived.

The shading represents the number of unique sites within the hectad that were included in the analysis. 


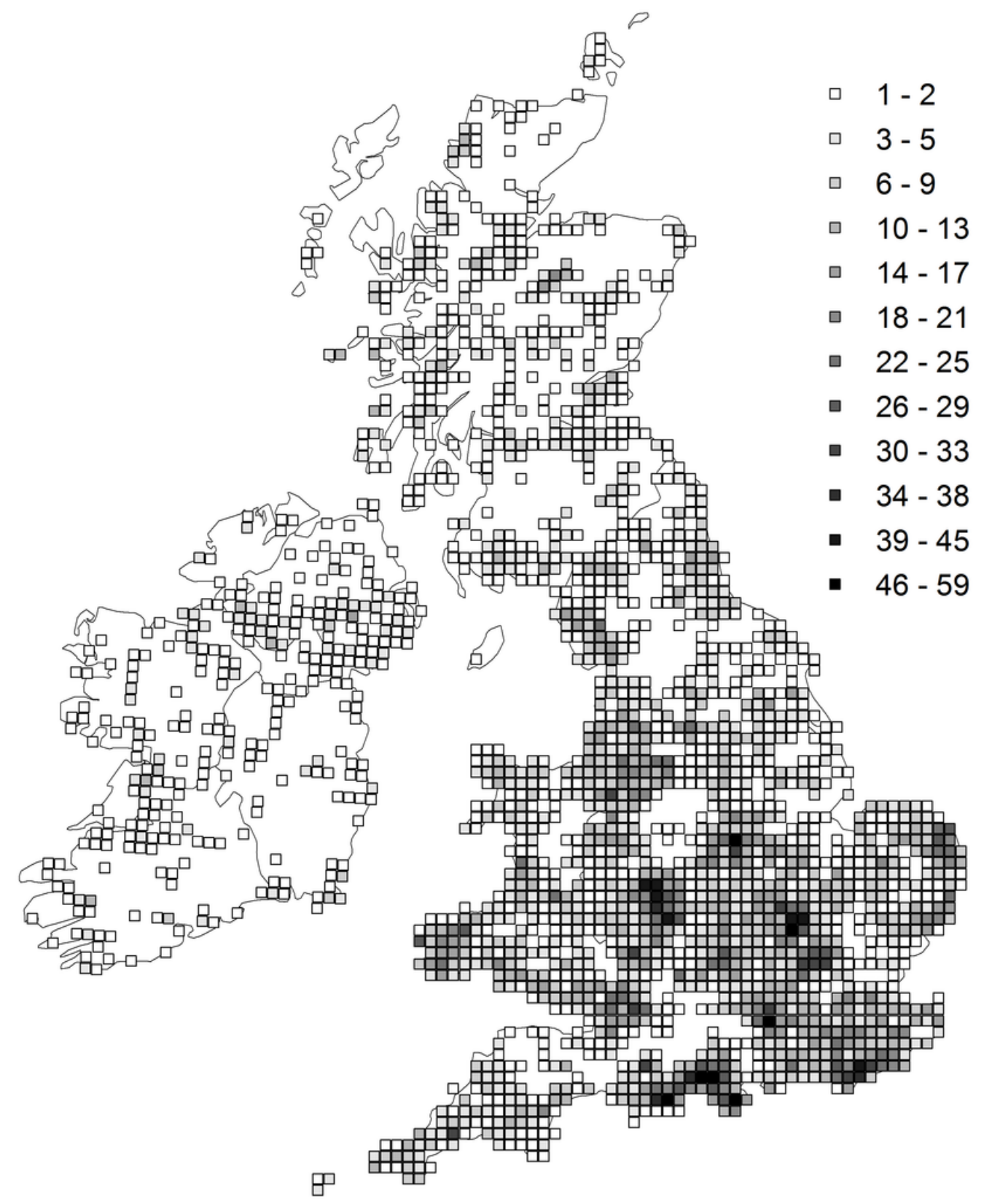


2

Figure 2 The mean and 95 percentiles of the trait coefficients across 10,000 model iterations.

Each categorical variable had a reference category which had a parameter estimate set to 0 . The reference categories were as follows: region = "southern", breeding habitat = "lentic", and for overwintering stage $=$ "eggs".

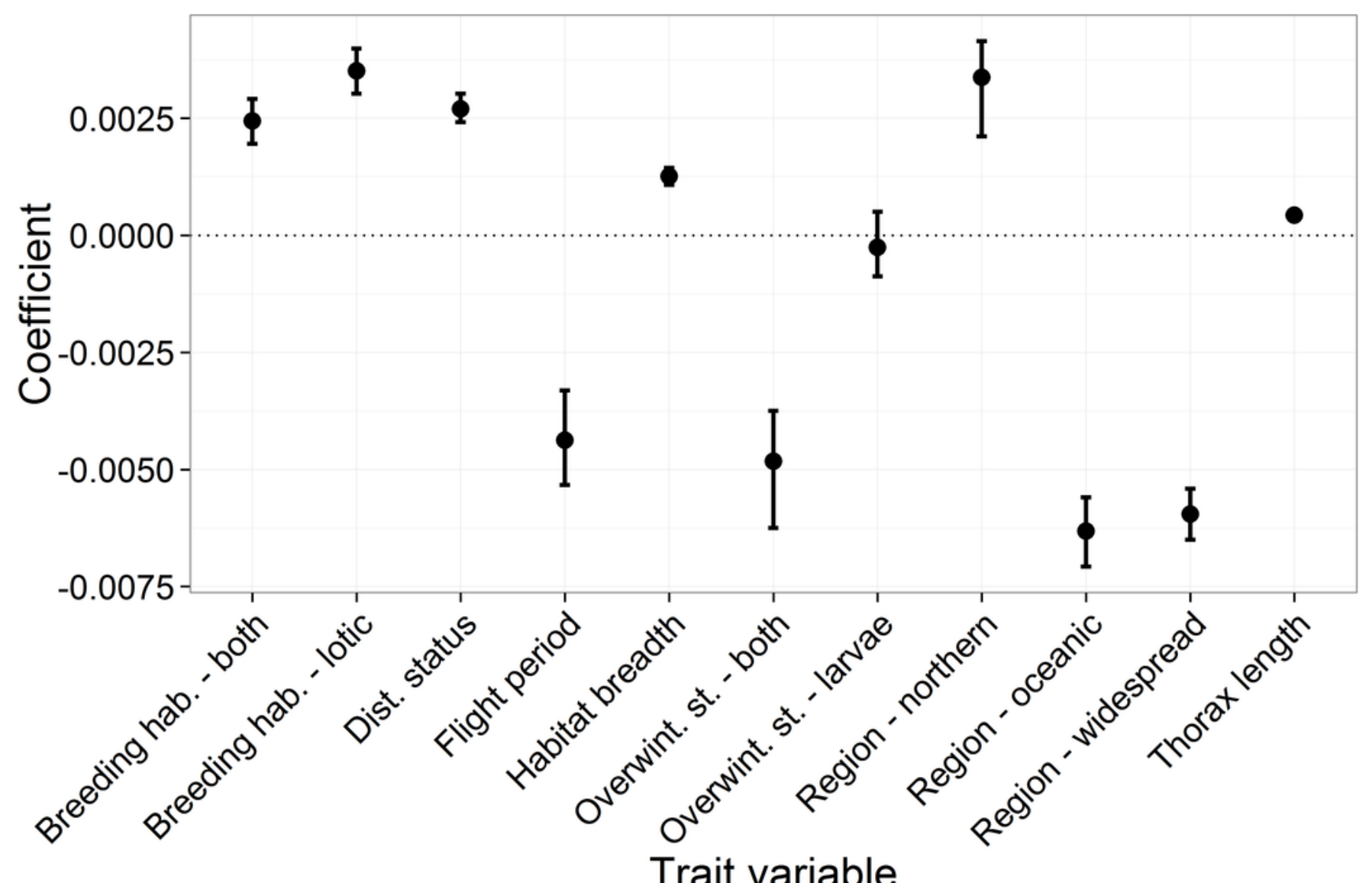




\section{Table $\mathbf{1}$ (on next page)}

Table 1. An overview of the Odonata traits included in the comparative analysis. 


\begin{tabular}{|c|c|c|}
\hline Trait & Description & Class \\
\hline Species status & $\begin{array}{l}\text { Species categorised on distribution size: very widespread, } \\
\text { widespread, local, scarce, rare, and very rare. }\end{array}$ & Ordinal \\
\hline Distribution region & $\begin{array}{l}\text { Broad climatic categorisation of species: widespread, } \\
\text { southern, northern or oceanic. }\end{array}$ & Categorical \\
\hline Thorax length & $\begin{array}{l}\text { Mean thorax length based on } 10 \text { adult ( } 5 \text { male and } 5 \\
\text { female) museum specimens ( } \mathrm{mm} \text { ). }\end{array}$ & Continuous \\
\hline Flight period & The duration of the flight period in months. & Continuous \\
\hline Habitat breadth & $\begin{array}{l}\text { A count of the number of habitat types utilised by the } \\
\text { species. }\end{array}$ & \\
\hline Breeding habitat & $\begin{array}{l}\text { Species were classified on their preferred breeding } \\
\text { habitat, either lentic, lotic or both. }\end{array}$ & Categorical \\
\hline Overwint. stage & $\begin{array}{l}\text { Species categorised as overwintering as larvae, eggs, or } \\
\text { both. }\end{array}$ & Categorical \\
\hline
\end{tabular}




\section{Table 2 (on next page)}

Table 2 The mean and 95 percentiles of the trait coefficients estimated from 10,000 model iterations.

The coefficients for the categorical variables (overwintering stage, region and breeding habitat) are shown as contrasts to the reference category (eggs, southern and lentic, respectively). The mean level of phylogenetic signal $(\lambda)$ across the 10,000 iterations is presented alongside its 95 percentiles. 
1

\begin{tabular}{llll}
\hline & & \multicolumn{2}{c}{ 95 Percentile } \\
\cline { 3 - 4 } Parameter & Mean coef. & $\mathbf{0 . 0 2 5}$ & $\mathbf{0 . 9 7 5}$ \\
\hline Thorax length & $4.87 \times 10^{-4}$ & $4.15 \times 10^{-4}$ & $5.65 \times 10^{-4}$ \\
Overwintering stage - both & -0.005 & -0.006 & -0.004 \\
Overwintering stage - larvae & $-2.82 \times 10^{-4}$ & $-9.58 \times 10^{-4}$ & $6.78 \times 10^{-4}$ \\
Flight period duration & -0.004 & -0.005 & -0.002 \\
Distribution status & 0.003 & 0.002 & 0.003 \\
Region - Northern & 0.003 & 0.001 & 0.004 \\
Region - Oceanic & -0.007 & -0.007 & -0.006 \\
Region - Widespread & -0.005 & -0.007 & -0.005 \\
Habitat breadth & 0.001 & 0.001 & 0.001 \\
Breeding habitat - both & 0.003 & 0.002 & 0.003 \\
Breeding habitat - lotic & 0.004 & 0.003 & 0.004 \\
$\lambda$ (phylo. signal) & 0.035 & $<0.001$ & 0.36 \\
\hline
\end{tabular}

2 